\title{
INFLUÊNCIA DA APLICAÇÃO DE NITROGÊNIO E FUNGICIDA NO ESTÁDIO DE EMBORRACHAMENTO SOBRE O DESEMPENHO AGRONÔMICO DO ARROZ IRRIGADO ( $\left.{ }^{1}\right)$
}

\author{
EDINALVO RABAIOLI CAMARGO $\left({ }^{2,3}\right)$; ENIO MARCHESAN $\left({ }^{*}, 3\right)$; TIAGO LUIS ROSSATO $\left({ }^{2,4}\right)$; \\ GUSTAVO MACK TELÓ $\left({ }^{2,4}\right)$; DIEGO ROST AROSEMENA $(2,5)$
}

\begin{abstract}
RESUMO
Limitações ao crescimento e desenvolvimento da planta de arroz provocados por deficiência nutricional, especialmente de nitrogênio e por doenças, afetam a capacidade fotossintética e a produtividade de grãos. O objetivo do trabalho foi avaliar o efeito da aplicação de nitrogênio e de fungicida no estádio de emborrachamento do arroz irrigado por inundação sobre a duração da área foliar fotossintetizante e a produtividade de grãos. O experimento foi desenvolvido no ano agrícola de 2005/2006, em área experimental de várzea do Departamento de Fitotecnia da Universidade Federal de Santa Maria. O delineamento experimental utilizado foi o de blocos ao acaso com quatro repetições. Os tratamentos, arranjados em esquema fatorial, constituíram-se de doses de nitrogênio $\left(50,100\right.$ e $\left.150 \mathrm{~kg} \mathrm{ha}^{-1}\right)$, perfazendo o fator A, e práticas de manejo realizadas durante o estádio de emborrachamento (aplicação suplementar de $30 \mathrm{~kg} \mathrm{ha}^{-1}$ de nitrogênio, pulverização com fungicida, combinação das duas práticas anteriores e um tratamento testemunha), que compuseram o fator $D$. As doses de nitrogênio utilizadas promoveram diferenças nas características avaliadas até o emborrachamento (número de colmos $\mathrm{m}^{-2}$, índice de área foliar e leitura SPAD); no entanto, não foi verificada interação entre os fatores estudados para as avaliações procedidas durante o período de enchimento de grãos. As práticas de manejo realizadas no emborrachamento não alteraram a área e a senescência foliar, a produtividade e os seus componentes. A baixa severidade de doenças foliares e o eficiente aproveitamento do nitrogênio, relacionados às condições ambientais favoráveis durante o ciclo da cultura, podem explicar, em parte, a falta de resposta às práticas de manejo utilizadas.
\end{abstract}

Palavras-chave: enchimento de grãos, Índice de área f-oliar, Oryza sativa L., senescência.

( ${ }^{1}$ Parte da dissertação de mestrado do primeiro autor, apresentada ao Programa de Pós-Graduação em Agronomia da Universidade Federal de Santa Maria. Recebido para publicação em 1. ${ }^{\circ}$ de novembro de 2006 e aceito em 20 de agosto de 2007.

$\left({ }^{2}\right)$ Universidade Federal de Santa Maria, Centro de Ciências Rurais, Departamento de Fitotecnia, Prédio 44, Sala 5335, 97105-970 Santa Maria (RS). E-mail: edinalvo_camargo@yahoo.com.br; emarch@ccr.ufsm.br (*) Autor correspondente.

$\left({ }^{3}\right)$ Bolsistas do Conselho Nacional de Desenvolvimento Científico e Tecnológico (CNPq).

$\left({ }^{4}\right)$ Bolsista da Fundação de Amparo à Pesquisa do Estado do Rio Grande do (FAPERGS).

$\left({ }^{5}\right)$ Bolsista da- Fundação de Apoio à Tecnologia e Ciência (FATEC). 


\title{
ABSTRACT \\ EFFECT OF NITROGEN AND FUNGICIDE APPLICATION AT BOOTING STAGE ON IRRIGATED RICE CROP PERFORMANCE
}

\begin{abstract}
Factors limiting rice plant growing and development caused by nutritional deficiency, especially by lack of nitrogen and diseases, affect the photosynthetic capacity and rice yield. The objective of this experiment was to evaluate the effect of the nitrogen and fungicide application on booting stage in order to verify photosynthetic area and rice yield. This work was conducted in 2005/2006 in lowland area in Santa Maria, RS, Brazil. The treatments were nitrogen rates $\left(50,100\right.$, and $\left.150 \mathrm{~kg} \mathrm{ha}^{-1}\right)$, composing the factor A, and management practices during the booting stage (supplementary application of $30 \mathrm{~kg} \mathrm{ha}^{-1}$ nitrogen, fungicide application, and the combination of the previous treatments, besides check treatment), composing the factor $\mathrm{D}$. The treatments were arranged in a randomized experimental block design, in a factorial scheme with four replications. The nitrogen rates promoted differentiated effects in the evaluated characteristics until booting stage (number of stem $\mathrm{m}^{-2}$, leaf area index and SPAD reading). However, there was not verified interaction among the treatments during rice grains filling. The management practices carried out on booting stage did not affect foliar area and senescence, yield and components of rice yield. The low occurrence of diseases, the efficiency of nitrogen utilization and the suitable climatic conditions for rice yield can explain the lack response to the management practices.
\end{abstract}

Key words: grain filling, Leaf area index, Oryza sativa L., senescence.

\section{INTRODUÇÃO}

Após o florescimento em plantas com hábito de crescimento determinado, ocorre naturalmente a redução da área e da atividade foliar. Este comportamento está associado à translocação de fotoassimilados (NTANOS e Koutroubas, 2002) e a redução da taxa fotossintética (ОоKAWA et al., 2003), que acarretam a senescência foliar. Na cultura do arroz irrigado por inundação, o declínio da capacidade fotossintética pode ocorrer precocemente durante o enchimento de grãos, período em que a fotossíntese é responsável por $60 \%$ a $100 \%$ do conteúdo final de carbono armazenado nos grãos (YosHIDA, 1981). O início da senescência foliar pode ser influenciado por determinadas práticas de manejo, sendo especialmente visualizada em situações de déficits nutricionais e com a ocorrência de doenças foliares.

A mobilidade do nitrogênio nas plantas e sua relação com o processo fotossintético fazem com que desempenhe um papel importante no acúmulo de massa seca nos grãos. Desta forma, a remobilização do nitrogênio foliar deve ocorrer concomitantemente com a ativa produção de fotoassimilados, devendo o conteúdo de nitrogênio ser suficiente para a manutenção da taxa fotossintética e, ainda, para que a redistribuição possibilite o adequado acúmulo de reservas nos grãos (Shiratsuchi et al., 2006). O manejo da adubação nitrogenada pode alterar a senescência foliar, dependendo da quantidade de fertilizante aportado e das condições ambientais para seu aproveitamento, podendo refletir na produtividade da cultura.

Assim, a utilização de nitrogênio após o desenvolvimento das estruturas reprodutivas, a fim de satisfazer um eventual déficit da planta ao final do ciclo, vem sendo estudada na cultura do arroz irrigado. Alguns trabalhos, avaliando o efeito da aplicação adicional de nitrogênio no estádio de emborrachamento, resultaram em incremento na produtividade (DingKUHN et al., 1992; WoPEREIS-PURA et al., 2002), decorrente dos benefícios providos pelo aumento da concentração de nitrogênio foliar na assimilação de $\mathrm{CO}_{2}$ (DINGKUHN et al., 1992).

Além do aspecto nutricional, a sanidade de plantas torna-se importante quando se busca a manutenção da atividade foliar ao longo da fase reprodutiva, ocasião em que a maioria dos patógenos instalam-se na planta. As doenças fúngicas da parte aérea diminuem a área foliar e, conseqüentemente, a capacidade de produção de fotoassimilados (BETHENOD et al., 2005) interferindo no enchimento de grãos. No Rio Grande do Sul, observa-se a freqüente ocorrência de doenças fúngicas, com destaque para as manchas foliares, na maioria das cultivares utilizadas atualmente. Assim, a aplicação de fungicidas tem propiciado incremento da produtividade da cultura em diferentes situações de cultivo (CELMER e BALARDIN, 2003; Fageria e Prabhu, 2004; Marzari et al., 2007).

A possibilidade de ampliar a duração da área foliar fotossintetizante, mantendo a taxa fotossintética, pela execução de determinadas práticas de manejo, pode refletir na produtividade, viabilizando a obtenção do potencial produtivo da espécie e das cultivares. Em visto do exposto, foi instalado um experimento com o objetivo de avaliar o efeito da aplicação de nitrogênio e de fungicida no estádio de emborrachamento, na duração da área foliar fotossintetizante e na produtividade de grãos do arroz irrigado. 


\section{MATERIAL E MÉTODOS}

O experimento foi desenvolvido durante o ano agrícola de 2005/2006, no Departamento de Fitotecnia da Universidade Federal de Santa Maria (latitude: $29^{\circ} 43^{\prime} \mathrm{S}$, longitude: $53^{\circ} 48^{\prime} \mathrm{W}$ e altitude: $95 \mathrm{~m}$ ), em um Planossolo Hidromórfico eutrófico arênico, com as seguintes características físico-químicas: argila $=34 \mathrm{~g}$ $\mathrm{kg}^{-1} ; \mathrm{pH}_{\text {água }}(1: 1)=5,7 ; \mathrm{P}=9,3 \mathrm{mg} \mathrm{dm}-3 ; \mathrm{K}=52 \mathrm{mg} \mathrm{dm}^{-3}$; $\mathrm{Ca}=7,5 \mathrm{cmol}_{\mathrm{c}} \mathrm{dm}^{-3} ; \mathrm{Mg}=3 \mathrm{cmol}_{\mathrm{c}} \mathrm{dm}^{-3}$ e M.O. $=25 \mathrm{~g} \mathrm{dm}^{-3}$. $\mathrm{O}$ delineamento experimental utilizado foi de blocos ao acaso com quatro repetições e as parcelas possuíam $10 \mathrm{~m} 2(5,0 \times 2,0 \mathrm{~m})$.

O preparo do solo para implantação da cultura foi realizado com gradagens e posterior aplainamento superficial do terreno, com o auxílio de aplanadora de solo. A semeadura realizada em 3 de novembro de 2005, utilizando-se $110 \mathrm{~kg} \mathrm{ha}^{-1}$ de sementes da cultivar IRGA 417, tratada com inseticida tiametoxam. A adubação fosfatada e potássica foi procedida pela distribuição na linha de semeadura de $45 \mathrm{~kg} \mathrm{ha}^{-1}$ de $\mathrm{P}_{2} \mathrm{O}_{5}$ e $90 \mathrm{~kg} \mathrm{ha}^{-1}$ de $\mathrm{K}_{2} \mathrm{O}$, correspondente à aplicação de $300 \mathrm{~kg} \mathrm{ha}^{-1}$ da formulação 0-15-30. A emergência das plântulas ocorreu 12 dias após a semeadura e o controle químico das plantas daninhas, a primeira aplicação do fertilizante nitrogenado (uréia) e a inundação definitiva da área foram realizadas aos 15 dias após a emergência (DAE). Os demais tratos culturais foram realizados conforme a recomendação técnica para a cultura.

Os 12 tratamentos estudados foram formados pela combinação de três doses de nitrogênio (fator A) e quatro práticas de manejo durante o estádio de emborrachamento (fator D). As doses de nitrogênio $\left(50,100\right.$ e $\left.150 \mathrm{~kg} \mathrm{ha}^{-1}\right)$ foram aplicadas em duas vezes. No início do perfilhamento, quando as plantas de arroz estavam no estádio V4, segundo a escala de desenvolvimento de Counce et al. (2000), aplicaram-se 20, 70 e $120 \mathrm{~kg} \mathrm{ha}^{-1}$ de nitrogênio em solo não-inundado e no estádio de iniciação da panícula (R0), executouse a aplicação da quantidade restante para cada dose.

As práticas de manejo realizadas no estádio de emborrachamento (R2) constaram da aplicação suplementar de $30 \mathrm{~kg} \mathrm{ha}^{-1}$ de nitrogênio, da pulverização com fungicida, da combinação de nitrogênio suplementar e fungicida, além de um tratamento testemunha (sem aplicação de nitrogênio e/ou fungicida no estádio R2). A aplicação de nitrogênio foi executada aos 74 dias (DAE), imediatamente após a emissão completa da folha bandeira, que caracteriza o início do estádio de emborrachamento. A aplicação de fungicida foi realizada aos $78 \mathrm{DAE}$, quando as plantas de arroz estavam no fim do estádio R2, dois dias antes da exserção da panícula (R3). A aplicação preventiva do fungicida foi realizada através da pulverização de propiconazol + trifloxistrobina, na dose de 93,75 + 93,75 $\mathrm{g} \mathrm{ha}^{-1}$, respectivamente, sendo a aplicação realizada com pulverizador costal de precisão pressurizado a $\mathrm{CO}_{2}$, utilizando-se $200 \mathrm{~L} \mathrm{ha}^{-1}$ de calda.

A avaliação da população inicial de plantas foi realizada aos $15 \mathrm{DAE}$, em um local representativo da unidade experimental, demarcando um metro na linha de semeadura e efetuando a contagem das plantas. No mesmo local, após o desbaste das plantas para homogeneizar a população em torno da média, foi executado o acompanhamento da emissão de colmos. A contagem para a estimativa do número de colmos foi feita semanalmente até os 57 DAE. Para quantificação do índice de área foliar, três plantas distribuídas uniformemente no metro linear demarcado foram marcadas e submetidas à avaliação não-destrutiva. A área foliar foi calculada pelo comprimento e largura de cada folha, multiplicado por 0,75 , exceto para a avaliação realizada aos 105 DAE onde se utilizou o coeficiente de 0,67 como fator de correção (YOSHIDA, 1981).

Os estádios de desenvolvimento foram determinados seguindo a escala proposta por COUNCE et al. (2000), objetivando a caracterização dos momentos de execução das principais práticas culturais. Para tal, na área de avaliação foram marcadas três plantas com arame colorido, executando-se duas verificações semanais no colmo principal. A leitura SPAD foi analisada por meio de um clorofilômetro, modelo SPAD 502 DL Meter (Minolta). O índice médio de cada tratamento foi resultante da observação de dez folhas do ápice (última folha completamente expandida), realizandose aferições nas extremidades e no centro de cada folha. Nas avaliações realizadas após a aplicação dos tratamentos no estádio de emborrachamento, as leituras foram executadas na última (bandeira) e penúltima folha.

Determinou-se também a senescência foliar através da observação visual das plantas na área da parcela. Para tanto, utilizou-se uma escala de 0 a 100, que corresponde à porcentagem de folhas totalmente verdes e totalmente senescentes (cloróticas), respectivamente (CARLESSO et al., 1998). A avaliação da severidade de doenças foliares também foi executada por meio de observações visuais, estimando-se porcentualmente a área foliar atacada. A produtividade de grãos foi estimada através da colheita manual de $6,0 \mathrm{~m}^{2}(5,0 \times 1,2 \mathrm{~m})$, quando havia nos grãos umidade média de $22 \%$. Após a trilha, limpeza e pesagem dos grãos com casca, os dados foram corrigidos para $13 \%$ de umidade e convertidos em kg ha-1. 
Os componentes da produtividade, número de panícula por metro quadrado, número de grãos por panícula, massa de mil grãos e esterilidade de espiguetas, foram determinados pela contagem das panículas no metro linear demarcado e pela coleta de 10 panículas por ocasião da colheita.

Os parâmetros avaliados foram submetidos à análise de variância e as médias comparadas pelo testes de Tukey $(\mathrm{P}=0,05)$. Os dados de índice de área foliar, senescência foliar, severidade de doenças e esterilidade de espiguetas foram transformados para $y t=\sqrt{y+0,5}$. Para os resultados expressos graficamente, determinou-se o intervalo de confiança $(\mathrm{P}=0,05)$.

\section{RESULTADOS E DISCUSSÃO}

A população de plantas do experimento ficou em torno de 200 plantas $\mathrm{m}^{-2}$, situando-se dentro da faixa preconizada para obtenção de altas produtividades. As doses de nitrogênio utilizadas promoveram diferenças nas características avaliadas anteriormente ao emborrachamento. A produção de colmos aumentou de forma distinta para as doses de nitrogênio, atingindo valores máximos com a formação do colar da décima folha (V10), momento em que foram quantificados 615 colmos $\mathrm{m}^{-2}$ no tratamento com $50 \mathrm{~kg} \mathrm{ha}^{-1}$ nitrogênio e 925 colmos $\mathrm{m}^{-2}$ no tratamento com aplicação de $150 \mathrm{~kg} \mathrm{ha}^{-1}$ (Figura 1A). A partir deste estádio, o número de colmos passou a decair, sendo o declínio mais acentuado nas doses maiores, proporcionando menores diferenças entre os tratamentos no estádio V12 (57 DAE). O efeito das doses de nitrogênio no comportamento do perfilhamento decorre basicamente da aplicação realizada no início do perfilhamento, uma vez que a aplicação em R0 foi realizada aos 50 DAE. MAE (1997) demonstra que o nitrogênio absorvido durante a fase vegetativa promove o rápido crescimento da planta e o aumento do número de perfilhos, determinando o número potencial de panículas, que é importante componente da produtividade.

A evolução do índice de área foliar (IAF) também foi influenciada pelas doses de nitrogênio, sendo as diferenças constatadas a partir de V10, ocasião em os tratamentos com dose de 100 e $150 \mathrm{~kg}$ $\mathrm{ha}^{-1}$ de nitrogênio possuíam IAF superior ao da dose de $50 \mathrm{~kg} \mathrm{ha}^{-1}$ (Figura 1B). Esta tendência persistiu até o estádio de emborrachamento, permitindo a obtenção de valores de IAF de 7,5 nas doses maiores, sendo $30 \%$ superior em relação à menor dose.

O número máximo de colmos $\mathrm{m}^{-2}$ foi alcançado anteriormente em relação ao máximo IAF. Para os dados aqui apresentados, as plantas deixam de emitir perfilhos com IAF de 2,3 na menor dose, enquanto na maior dose o IAF crítico atinge 3,6. Comportamento similar foi observado por ZHONG et al. (2002) em estudo relacionando o IAF e a taxa de perfilhamento. Os autores estabeleceram valores críticos de IAF, a partir do qual a emissão de perfilhos deixa de ocorrer, sendo estes afetados pelo nível de nitrogênio aportado.
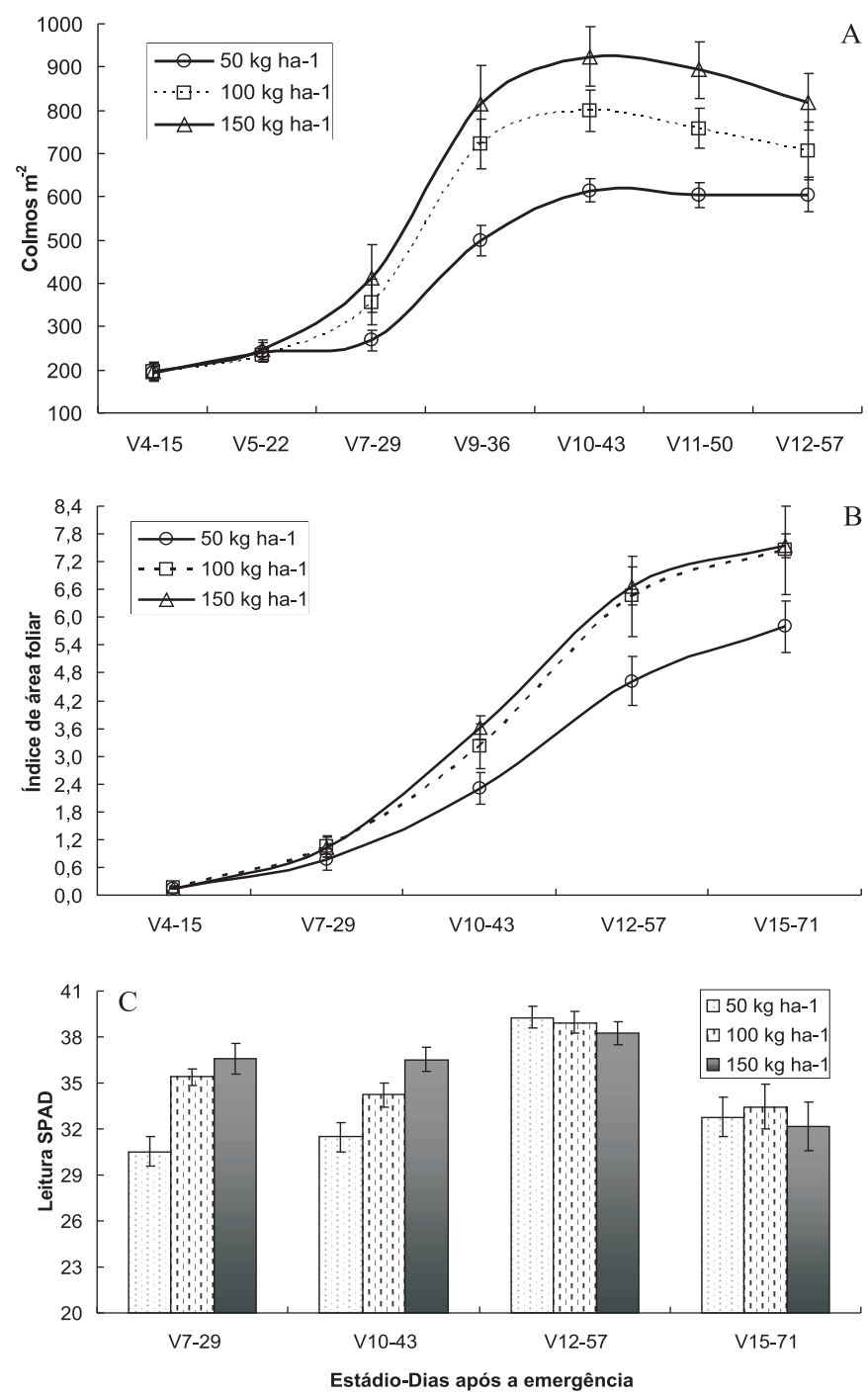

Figura 1. Número de colmos $\mathrm{m}^{-2}(\mathrm{~A})$, índice de área foliar (B) e leitura SPAD (C) para as três doses de nitrogênio (fator A) nas avaliações procedidas anteriormente à aplicação dos manejos no estádio de emborrachamento da cultura do arroz irrigado.

Para as leituras SPAD, observa-se que os valores aumentaram conforme o acréscimo das doses de nitrogênio nas avaliações realizadas nos estádios V7 e V10. No entanto, as diferenças deixaram de existir nas avaliações subseqüentes, o que pode ser em decorrência da aplicação de doses idênticas no estágio R0 (50 DAE), que equilibrou os valores na última folha expandida (Figura 1C). A absorção e 
translocação do nitrogênio para as folhas novas propiciaram aumento no índice SPAD, que se situava em 34 na avaliação realizada em V10 e passou para 39 na avaliação realizada em V12, demonstrando a importância deste nutriente para a formação do aparato fotossintético (MAE, 1997). O acompanhamento da leitura SPAD até o estádio de emborrachamento foi utilizado por PENG et al. (1996) para manejar o fertilizante nitrogenado, realizando a aplicação de cobertura quando o valor estivesse abaixo de 35 . Com esse método, os autores conseguiram aumentar a eficiência da adubação nitrogenada. No presente trabalho, este valor referencial não foi alcançado até o estádio V12 na dose de $50 \mathrm{~kg} \mathrm{ha}^{-1}$ de nitrogênio e no estádio V15 situava-se em patamar inferior para todas as doses de nitrogênio. Ressalta-se que existem diferenças genéticas a serem consideradas e que podem determinar variações para as leituras SPAD entre diferentes cultivares.

Tabela 1. Índice de área foliar (IAF), senescência e severidade de doenças foliares aos 90 (R6) e 105 (R8) dias após a emergência, em resposta a doses de nitrogênio e a distintos manejos aplicados durante o estádio de emborrachamento da cultura do arroz irrigado

\begin{tabular}{|c|c|c|c|c|c|c|}
\hline \multirow{2}{*}{ Doses de nitrogênio } & \multicolumn{2}{|c|}{ IAF } & \multicolumn{2}{|c|}{ Senescência (\%) } & \multicolumn{2}{|c|}{ Severidade (\%) } \\
\hline & R6 $\left({ }^{1}\right)$ & $\mathrm{R} 8\left(^{1}\right)$ & R6 & R8 & R6 & R8 \\
\hline $50 \mathrm{~kg} \mathrm{ha}^{-1}$ & $4,9 \mathrm{~ns}$ & $2,1 \mathrm{~ns}$ & $7 \mathrm{~ns}$ & $44 \mathrm{a}$ & $0,1 \mathrm{~b}$ & $1,3 \mathrm{~ns}$ \\
\hline $100 \mathrm{~kg} \mathrm{ha}^{-1}$ & 5,7 & 2,5 & 9 & $38 \mathrm{~b}$ & $0,1 \mathrm{~b}$ & 1,2 \\
\hline $150 \mathrm{~kg} \mathrm{ha}^{-1}$ & 5,9 & 2,8 & 8 & $30 \mathrm{c}$ & $0,3 \mathrm{a}$ & 1,0 \\
\hline \multicolumn{7}{|l|}{ Manejo em R2 $\left({ }^{1}\right)$} \\
\hline Testemunha & $4,9^{\text {ns }}$ & $2,4^{\mathrm{ns}}$ & $7^{\mathrm{ns}}$ & $39^{\text {ns }}$ & $0,3 \mathrm{a}$ & $1,7 \mathrm{a}$ \\
\hline Fungicida (F) & 5,4 & 2,4 & 7 & 39 & $0,1 \mathrm{ab}$ & $0,8 \mathrm{~b}$ \\
\hline $\mathrm{N}$ suplementar $(\mathrm{N})$ & 5,3 & 2,2 & 9 & 37 & $0,2 \mathrm{ab}$ & $1,5 \mathrm{ab}$ \\
\hline $\mathrm{F}+\mathrm{N}$ & 6,2 & 3,0 & 9 & 35 & $0,0 \mathrm{~b}$ & $0,8 \mathrm{~b}$ \\
\hline Média & 5,5 & 2,5 & 8 & 37 & 0,2 & 1,2 \\
\hline $\mathrm{C} . \mathrm{V} .=$ & 11,1 & 13,8 & 19,8 & 7,8 & 15,3 & 18,4 \\
\hline
\end{tabular}

( $\left.{ }^{1}\right)$ Estádio de desenvolvimento segundo escala proposta por COUNCE et al. (2000)..

ns:Teste $F$ não significativo $(\mathrm{P}=0,05)$. Médias não seguidas pela mesma letra diferem entre si pelo Teste de Tukey $(\mathrm{P}=0,05)$.

Não foi verificada interação entre os fatores estudados para as avaliações procedidas durante o período de enchimento de grãos. O IAF foi semelhante entre as doses de nitrogênio e entre os manejos realizados durante o estádio de emborrachamento, embora em valores absolutos o IAF tenha aumentado com incremento da doses de nitrogênio (Tabela 1). Destaca-se a redução da área foliar em $55 \%$, desde a elongação de pelo menos uma cariopse à extremidade da casca (R6) até a formação de grãos com casca marrom (R8), indicando a translocação de fotoassimilados das folhas (fonte) para os grãos (dreno). As folhas são as maiores fontes de nitrogênio para a remobilização, sendo um processo que acelera a senescência foliar e resulta em rápido decréscimo da atividade fotossintética (MAe, 1997). Por outro lado, TAKai et al. (2006) demonstram a importância da fotossíntese no dossel vegetativo durante a fase reprodutiva e os autores relatam ser este o próximo passo em direção ao aumento do potencial produtivo.

A senescência foliar foi retardada com o aumento das doses de nitrogênio na avaliação realizada no estádio $\mathrm{R} 8$, momento em que se aproximava a colheita. Os manejos realizados durante o estádio de emborrachamento não alteraram o decréscimo da área foliar que continuou ocorrendo de R6 para R8 e igualmente não influenciaram a senescência foliar. Apesar de ser influenciada pelos tratamentos, especialmente pela aplicação de fungicida, a severidade de doenças foliares foi baixa, sendo insuficiente para causar prejuízos à área foliar e à produtividade. $\mathrm{O}$ índice SPAD decresceu nas avaliações realizadas durante o período de enchimento de grãos. As principais diferenças observadas relacionaram-se principalmente com as doses de nitrogênio aplicadas na fase vegetativa (Figura 2A). $\mathrm{O}$ incremento das doses de nitrogênio aumentou o índice SPAD tanto na folha bandeira como na penúltima folha. Na avaliação realizada em R7, observa-se que as leituras foram menores na penúltima folha, especialmente na menor dose de nitrogênio. Esse fato decorre da liberação de nitrogênio das folhas mais velhas, para suprir a atividade metabólica das folhas novas e dos grãos (KAMACHI et al., 1991). Para os manejos feitos durante a fase de emborrachamento, apesar de existir uma tendência de superioridade nos tratamentos com aplicação suplementar de nitrogênio, os valores não diferem estatisticamente (Figura 2B). 

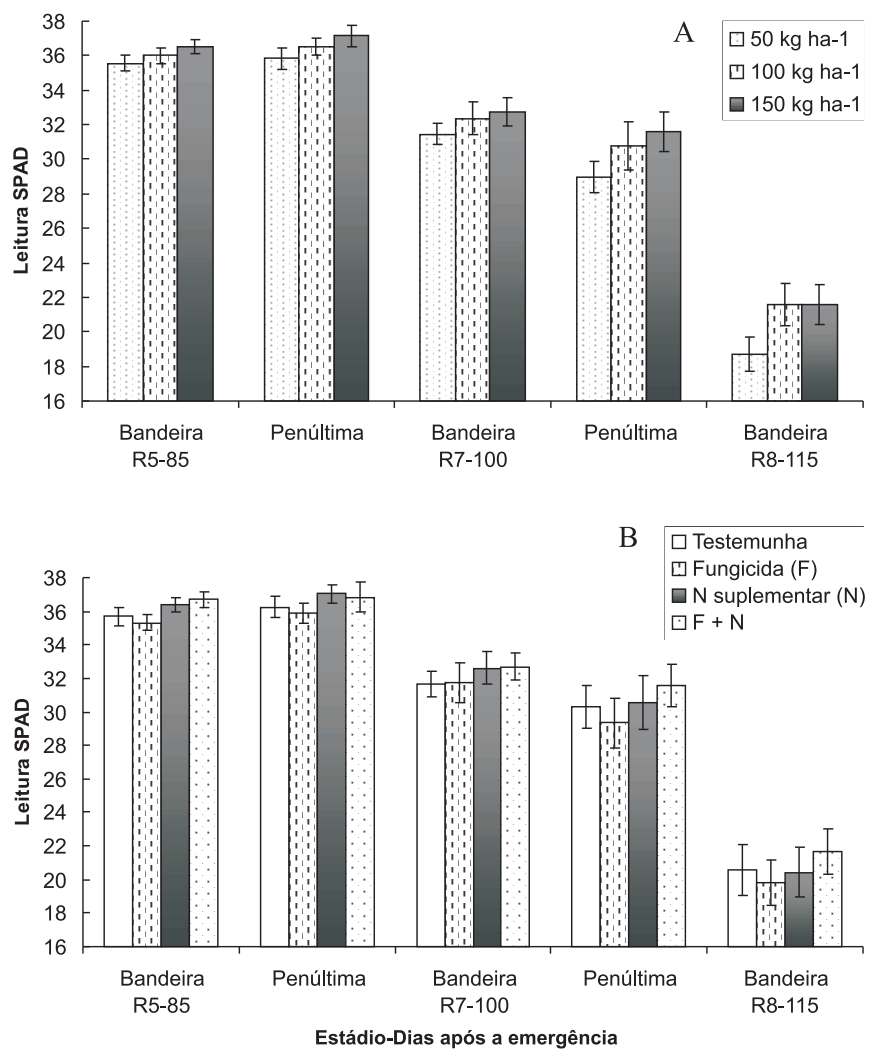

Figura 2. Leitura SPAD na última (bandeira) e penúltima folha em resposta às doses de nitrogênio $(\mathrm{A})$ e a distintos manejos realizados durante estádio de emborrachamento (B) da cultura do arroz irrigado.

Semelhante aos demais parâmetros avaliados, não houve interação entre os fatores estudados para a produtividade de grãos. Com relação às doses de nitrogênio, obteve-se produtividade ao redor de
$10.000 \mathrm{~kg}$ ha-1 com a utilização de 100 e $150 \mathrm{~kg} \mathrm{ha}^{-1}$ de nitrogênio, sendo superior àquela obtida com 50 $\mathrm{kg} \mathrm{ha}^{-1}$ de nitrogênio (Tabela 2). Da mesma forma, o maior número de panículas por metro quadrado foi alcançado nas maiores doses, evidenciando a relação entre a produtividade e o efeito do fertilizante nitrogenado na formação dos componentes da produtividade, no aumento do aparato fotossintético e no acúmulo de fotoassimilados durante a fase que antecede a emissão das panículas. NTANOS e KoutrobAS (2002) relatam que a maior quantidade de massa seca e nitrogênio acumulados até o florescimento resultam em maiores quantidades de carbono e nitrogênio translocados para os grãos.

Para as condições de realização do trabalho, os manejos realizados durante o estádio de emborrachamento não influenciaram a produtividade e os seus componentes. A baixa severidade de doenças foliares e o eficiente aproveitamento dos fertilizantes nitrogenados, relacionados às condições ambientais favoráveis durante o ciclo da cultura, podem explicar em parte, a falta de resposta às práticas de manejo no período reprodutivo. A ocorrência de radiação solar acima da normal de novembro a março (dados não mostrados), propiciou condições energéticas para a plena atividade fotossintética, condicionando o aproveitamento do nitrogênio aplicado anteriormente ao estádio de emborrachamento. Além disso, verificaram-se precipitações pluviais abaixo da normal, especialmente em fevereiro, que coincidiu com o florescimento da cultura e reduziu a ocorrência de patógenos foliares. Destaca-se também a ausência de temperaturas baixas prejudiciais na fase reprodutiva, conforme se observa pelos baixos valores de esterilidade de espiguetas obtidos no experimento.

Tabela 2. Produtividade, panículas por metro quadrado (PMQ), número de grãos por panícula (GP), massa de mil grãos (MMG) e esterilidade de espiguetas (EE), em resposta às doses de nitrogênio e a distintos manejos realizados durante o estádio de emborrachamento do arroz irrigado

\begin{tabular}{|c|c|c|c|c|c|}
\hline Doses de nitrogênio & Produtividade & PMQ & GP & MMG & $\mathrm{EE}$ \\
\hline & $\mathrm{kg} \mathrm{ha}^{-1}$ & & & $\mathrm{~g}$ & $\%$ \\
\hline $50 \mathrm{~kg} \mathrm{ha}^{-1}$ & $9.313 \mathrm{~b}$ & $469 \mathrm{~b}$ & $77 \mathrm{~ns}$ & $25,9 \mathrm{~ns}$ & $4,1 \mathrm{~ns}$ \\
\hline $100 \mathrm{~kg} \mathrm{ha}^{-1}$ & $9.910 \mathrm{a}$ & 515 a & 83 & 25,8 & 3,9 \\
\hline $150 \mathrm{~kg} \mathrm{ha}^{-1}$ & $10.125 \mathrm{a}$ & $514 \mathrm{a}$ & 84 & 25,6 & 4,6 \\
\hline \multicolumn{6}{|l|}{ Manejo em R2 ( $\left.{ }^{1}\right)$} \\
\hline Testemunha & $9.904 n s$ & $515 \mathrm{~ns}$ & $82 \mathrm{~ns}$ & $25,4 \mathrm{~ns}$ & $4,1 \mathrm{~ns}$ \\
\hline Fungicida (F) & 10.066 & 480 & 83 & 25,8 & 4,0 \\
\hline $\mathrm{N}$ suplementar $(\mathrm{N})$ & 9.451 & 488 & 82 & 25,9 & 4,4 \\
\hline $\mathrm{F}+\mathrm{N}$ & 9.711 & 515 & 78 & 26,0 & 4,3 \\
\hline Média & 9.783 & 500 & 81 & 25,8 & 4,2 \\
\hline$C . V .=$ & 6,5 & 10,4 & 12,5 & 3,4 & 13,1 \\
\hline
\end{tabular}

$\left({ }^{1}\right)$ Estádio de desenvolvimento segundo escala proposta por Counce et al. (2000).

${ }^{n s}$ :Teste F não significativo $(P=0,05)$. Médias não seguidas pela mesma letra diferem entre si pelo Teste de Tukey $(P=0,05)$. 


\section{CONCLUSÕES}

1. A aplicação de nitrogênio nos estádios que antecedem o emborrachamento contribui para a formação do número de panículas $\mathrm{m}^{-2}$, para o aumento do aparato fotossintético, para o acúmulo de fotoassimilados e para a produtividade.

2. A aplicação suplementar de nitrogênio e o uso de fungicida no emborrachamento, em condições de baixa severidade de doenças foliares e sem restrições climáticas, não afetam a duração da área foliar fotossintetizante, os componentes e a produtividade de grãos de arroz de arroz irrigado.

\section{AGRADECIMENTOS}

Ao Conselho Nacional de Desenvolvimento Científico e Tecnológico (CNPq), à Fundação de Amparo à Pesquisa do Estado do Rio Grande do Sul (FAPERGS) e ao Fundo de Incentivo à Pesquisa (FIPE) pelo suporte financeiro e pelas bolsas de estudo e produtividade concedidas. Ao Instituto Rio Grandense do Arroz (IRGA) pelo empréstimo do clorofilômetro.

Os autores agradecem ainda aos demais integrantes do Grupo de Pesquisa em Arroz e Uso Alternativo de Várzea pela assistência durante a realização do experimento.

\section{REFERÊNCIAS}

BETHENOD, O.; Le CORRE, M.; HUBER, L.; SACHE, I. Modelling the impact of brown rust on wheat crop photosynthesis after flowering. Agricultural and Forest Meteorology, Amsterdam, v.131, p.41-53, 2005.

CARLESSO, R.; HERNANDEZ, M.G.R.; RIGHES, A.A.; JADOSKI, S.O. Índice de área foliar e altura de plantas de arroz submetidas a diferentes práticas de manejo. Revista Brasileira de Engenharia Agrícola e Ambiental, Campina Grande, v.2-3, p.268-272, 1998.

CELMER, A.F.; BALARDIN, R.S. Danos devido a doenças foliares no arroz irrigado. In: CONGRESSO BRASILEIRO DE ARROZ IRRIGADO, 3; REUNIÃO DA CULTURA DO ARROZ IRRIGADO, 25; 2003, Itajaí, SC. Anais... Itajaí: EPAGRI, 2003. p.326-328.

COUNCE, P.A.; KEISLING, T.C.; MITCHELL, A.J. A uniform, objective and adaptive system for expressing rice development. Crop Science, Madison, n.40, p.436-443, 2000.

DINGKUHN, M.; de DATTA, S.K.; JAVELLANA, C.; PAMPLONA, R.; SCHNIER, H.F. Effect of late-season N fertilization on photosynthesis and yield of transplanted and direct-seeded tropical flooded rice. I. Growth dynamics. Field Crops Research, Amsterdam, v.28, 223-234, 1992.
FAGERIA, N,K.; PRABHU, A.S. Controle de brusone e manejo de nitrogênio em cultivo de arroz irrigado. Pesquisa Agropecuária Brasileira, Brasília, v.39, n.2, p.123-129, 2004.

KAMACHI, K.; YAMAYA, T.; MAE, T.; OJIMA, K. A role for glutamine synthetase in the remobilization of leaf nitrogen during natural senescence in rice leaves. Plant Physiology, v.96, p.411-417, 1991.

MAE, T. Physiological nitrogen efficiency in rice: nitrogen utilization, photosynthesis, and yield potential. Plant and Soil, Sofia, v.196, p.201-210, 1997.

MARZARI, V et al. População de plantas, doses de nitrogênio e a aplicação de fungicida na produção de arroz irrigado. I. Características agronômicas. Ciência Rural, Santa Maria, v.37, n.2, 2007.

NTANOS, D.A.; KOUTROUBAS, S.D. Dry matter and N accumulation and translocation for Indica and Japonica rice under Mediterranean conditions. Field Crops Research, Amsterdam, v.74, p.93-101, 2002.

OOKAWA, T.; NARUOKA, Y.; YAMAZAKI, T.; SUGA, J.; HIRASAWA, T. A comparasion of the accumulation and partitioning of nitrogen in plants between two rice cultivares, Akenohoshi and Nipponbare, at the ripening stage. Plant Production Science, Shinkawa, v.6, n.3, p.172-178, 2003.

PENG, S.; GARCIA, F.V.; LAZA, R.C. SANICO, A.L. VISPERAS, R.M.; CASSMAN, K.G. Increased N-use efficiency using a chlorophyll meter on high-yielding irrigated rice. Field Crops Research, Amsterdam, v.47, p.243-252, 1996.

SHIRATSUCHI, H.; YAMAGISHI, T.; ISHII, R. Leaf nitrogen distribution to maximize the canopy photosynthesis in rice. Field Crops Research, Amsterdam, v.95, p.291-304, 2006.

TAKAI, T.; MATSUURA, S.; NISHIO, T. OHSUMI, A.; SHIRAIWA, T.; HORIE, T. Rice yield potential is closely related to crop growth rate during late reproductive period. Field Crops Research, Amsterdam, v.96, p.328-335, 2006.

WOPEREIS-PURA, M.M.; WATANABE, H.; MOREIRA, J.; WOPEREIS, M.C.S. Effect of late nitrogen application on rice yield, grain quality and profitability in the Senegal River valley. European Journal of Agronomy, v.17, p.191-198, 2002.

YOSHIDA, S. Fundamental of rice crop science. Los Baños: International Rice Research Institute, 1981. 269p.

ZHONG, X.; PENG, S.; SHEEHY, J.E.; VISPERAS, R.M.; LIU, H. Relationship between tillering and leaf area index: quantifying critical leaf area index for tillering in rice. Journal of Agriculture Science, Cambridge, v.138, p.269-279, 2002. 